\title{
NOTES
}

\section{Dielectric Anisotropy of Strip Polymer Films at Microwave Frequencies}

\author{
Shigeyoshi OsAKI \\ Mycal Institute Inc., 2-2-9, Awajimachi, Chuo-ku, Osaka 541, Japan
}

(Received March 8, 1993)

KEY WORDS Dielectric Constant / Dielectric Loss / Microwave Frequency

/ Strip Sample / Anisotropy / Polymer Film /

Recently, we have developed a new microwave method that permits quick and contactfree measurement of the dielectric anisotropy of sheet materials. ${ }^{1-12}$ Though promising, this method has a shortcoming that it needs a sample of relatively large size in comparison with that used for X-ray diffraction. Thus, it is of no practical use when such samples cannot be easily prepared.

To check the scope of applicability we have attempted to measure dielectric anisotropy of polymer films with relatively small widths by our microwave method. The results obtained are reported below. The description includes a modification of the standard working equation to one adequate for the evaluation of the dielectric constant at microwave frequencies.

\section{EXPERIMENTAL}

The samples used in this work were tetrafluoroethylene-hexafluoroethylene copolymer (T-H copolymer) films $150 \mu \mathrm{m}$ thick, uniaxially stretched poly(ethylene terephthalate) (PET) films $410 \mu \mathrm{m}$ thick and uniaxially stretched poly(vinylidene fluoride) (PVDF) film $75 \mu \mathrm{m}$ thick. Each was $100 \mathrm{~mm}$ long and $2 \mathrm{~mm}$ to $100 \mathrm{~mm}$ wide. The long axis was parallel to the machine direction MD. Polarized microwaves were incident perpendicularly to the plane of the sample. The sample strip mounted in a holder made of poly(vinyl chloride) sheets was inserted in a narrow gap between a pair of rectangular waveguides of the cavity resonator system and they were set in the center of the waveguides so that the electric field was parallel or perpendicular to the long axis of the strip. The dielectric constant $\varepsilon^{\prime}$ and dielectric loss $\varepsilon^{\prime \prime}$ at $4.0 \mathrm{GHz}$ were determined by measuring the resonance frequencies and the $Q$-values in the resonator system at rotation angles of $0^{\circ}$ and $90^{\circ}$. Here, the resonance frequency is defined as the frequency at which the transmitted microwave intensity shows a maximum in the resonance curve, and the $Q$-value as the ratio of the resonance frequency to the half width of the resonance curve. The time needed for each dielectric measurement at a fixed rotation angle was $30 \mathrm{~s}$. The electro-magnetic mode used was a transverse electric wave (TE) of a type of $\mathrm{TE}_{10 \mathrm{~L}}$ with $\mathrm{L}$ being an odd number. ${ }^{13}$ The measuring frequencies were from 3.6 to $4.2 \mathrm{GHz}$. All measurements were made at $20^{\circ} \mathrm{C}$ and $65 \%$ RH.

\section{EVALUATION OF COMPLEX DIELECTRIC CONSTANT}

A perturbation theory is applicable for the determination of the complex dielectric constant when $\varepsilon^{\prime \prime}$ is very small and the frequency shift is much smaller than the resonance frequency before inserting the sample.

The complex dielectric constant $\varepsilon^{*}\left(=\varepsilon^{\prime}-\right.$ 
$\left.j \varepsilon^{\prime \prime}\right)$ for a dielectric material is expressed $b y^{4,6}$

$$
\varepsilon^{*}(\theta)=1-\frac{\left(\omega_{2}(\theta)-\omega_{1}\right)}{\omega_{2}(\theta)} \frac{2 \int_{V_{c}}\left|E_{1}\right|^{2} \mathrm{~d} V}{\int_{V_{\mathrm{s}}}\left|E_{1}\right|\left|E_{2}\right| \mathrm{d} V}
$$

where $\omega$ is the complex angular frequency, $E$ the electric field in the cavity, $V_{\mathrm{c}}$ the total volume of the cavity, $V_{\mathrm{s}}$ the volume of the sample, and the subscripts 1 and 2 refer to the values before and after insertion of the sample, respectively, all at a rotation angle of $\theta$.

When the sample is a sheet material and its size is smaller than that of the opening of each waveguide, the electric field in the cavity can be substituted for $E$ in eq 1 , and the integrals are evaluated to give

$$
\begin{aligned}
& \varepsilon^{\prime}(0)=1+A(a c / t d)\left[f_{1}-f_{2}(0)\right] / f_{2}(0) \\
& \varepsilon^{\prime \prime}(0)=B(a c / 2 t d)\left[1 / Q_{2}(0)-1 / Q_{1}\right]
\end{aligned}
$$

and

$$
\begin{aligned}
& \varepsilon^{\prime}(90)=1+F(b c / t d)\left[f_{1}-f_{2}(90)\right] / f_{2}(90) \\
& \varepsilon^{\prime \prime}(90)=G(b c / 2 t d)\left[1 / Q_{2}(90)-1 / Q_{1}\right]
\end{aligned}
$$

at $\theta=0^{\circ}$ and $\theta=90^{\circ}$, respectively, for the sheet set in the center of the waveguides. Here, $a$ and $b$ are the widths of the long and short axes of each waveguide, respectively, $A, B, F$, and $G$ are constants associated with the instrument, $c$ is a parameter related to the depth of the rectangular waveguide, $t$ is the thickness of the sample, and $d$ is the width of the sample.

\section{RESULTS AND DISCUSSION}

Figure 1 shows the dependence of $\varepsilon^{\prime}$ at $4.0 \mathrm{GHz}$ on sample width for $\mathrm{T}-\mathrm{H}$ polymer films with a $150 \mu \mathrm{m}$, determined when the long axis corresponding to the MD is parallel and perpendicular to the electric field. We see that these $\mathbf{T}-\mathbf{H}$ polymer films are randomly oreinted. The variation in $\varepsilon^{\prime}$ with sample width is almost negligible in either MD or TD (transverse direction perpendicular to the MD)

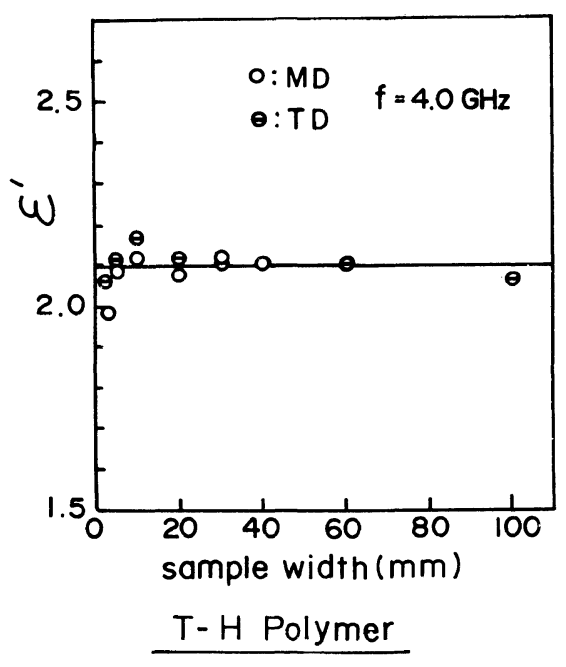

Figure 1. Dependence of $\varepsilon^{\prime}$ at $4.0 \mathrm{GHz}$ on sample width for tetrafluoroethylene-hexafluoroethylene copolymer ( $T$ $\mathrm{H}$ polymer) films with a thickness of $150 \mu \mathrm{m}$.

direction; $\varepsilon^{\prime}$ for each is close to 2.1 , with the standard deviation 0.027 . This value of $\varepsilon^{\prime}$ agrees with those reported previously for $\mathrm{T}-\mathrm{H}$ polymer films (Figure 1 of ref 6).

Figure 2 shows the dependence of $\varepsilon^{\prime}$ at $4.0 \mathrm{GHz}$ on sample width for uniaxially stretched PET films with a $410 \mu \mathrm{m}$. Over the entire range of sample width studied $\varepsilon^{\prime}$ is almost constant, and is larger in the MD than in the TD. It was found that these $\varepsilon^{\prime}$ values are close to that of a sample with a conventional size of $100 \mathrm{~mm} \times 100 \mathrm{~mm}$. This is similar to what we found in previous work (see Figure 3 of ref 4 ).

Figure 3 shows the dependence of $\varepsilon^{\prime}$ and $\varepsilon^{\prime \prime}$ at $4.0 \mathrm{GHz}$ on sample width for uniaxially stretched PVDF films with a $75 \mu \mathrm{m}$. The values of $\varepsilon^{\prime}$ and $\varepsilon^{\prime \prime}$ determined in either MD or TD direction remain almost unchanged with sample width. They are larger in the TD than in the MD. These results are consistent with those reported in ref 9. Although small variations in $\varepsilon^{\prime}$ and $\varepsilon^{\prime \prime}$ are observed in Figures 2 and 3, they are most likely due to errors in measurements of sample width, difference in the position of a film sheet where the specimen was cut from and variation of the position in 

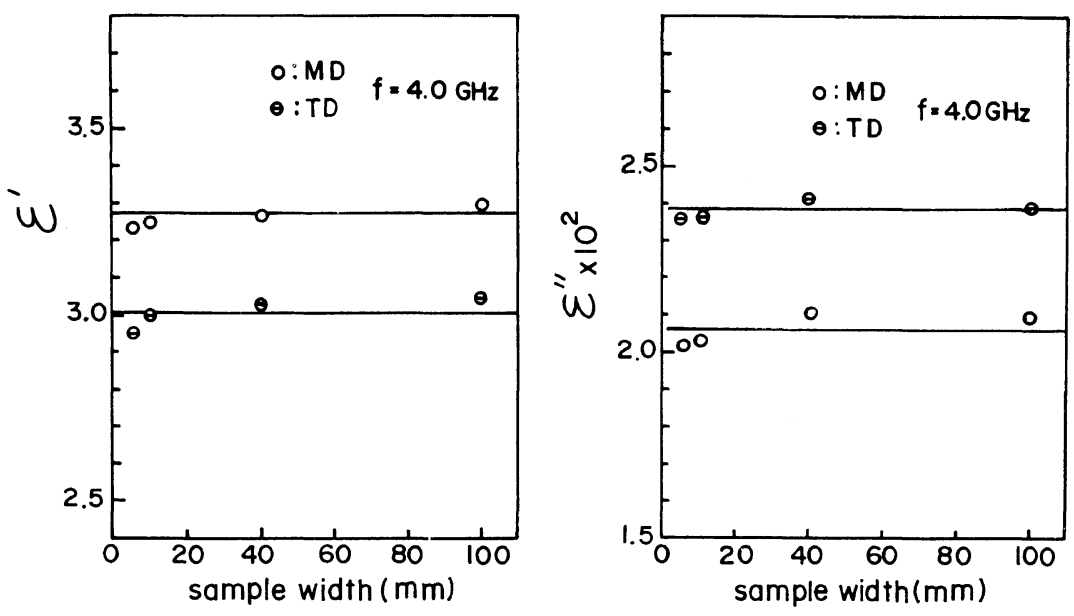

uniaxially stretched PET

Figure 2. Dependence of $\varepsilon^{\prime}$ and $\varepsilon^{\prime \prime}$ at $4.0 \mathrm{GHz}$ on sample width for uniaxially stretched poly(ethylene terephthalate) (PET) films with a thickness of $410 \mu \mathrm{m}$.
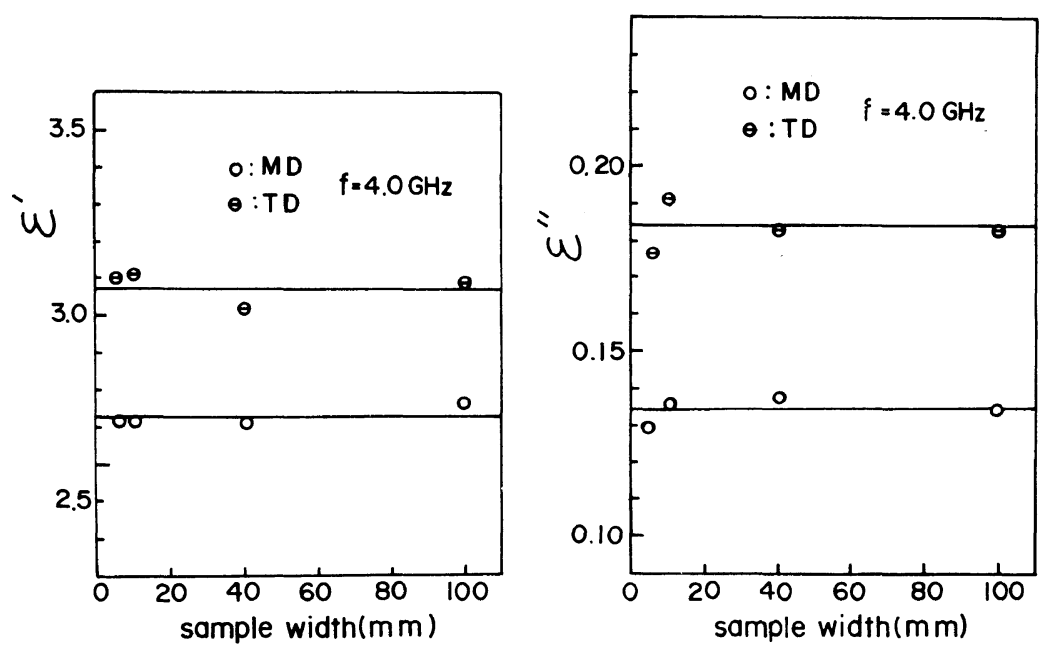

uniaxially stretched PVDF

Figure 3. Dependence of $\varepsilon^{\prime}$ and $\varepsilon^{\prime \prime}$ at $4.0 \mathrm{GHz}$ on the sample width for uniaxially stretched poly(vinylidene fluoride) (PVDF) films with a thickness of $75 \mu \mathrm{m}$.

the resonator system where the specimen was set.

The above results substantiate that eq 2 to 5 are applicable to strip films wider than $2 \mathrm{~mm}$. At present, it is very difficult to determine $\varepsilon^{\prime}$ and $\varepsilon^{\prime \prime}$ at $4.0 \mathrm{GHz}$ for strip films narrower than $2 \mathrm{~mm}$ by use of our microwave method, but these equations should be applicable to such films if their $\varepsilon^{\prime}$ and $\varepsilon^{\prime \prime}$ are large enough.

In conclusion, the present method using the modified equations described above is useful for studying the dielectric anisotropy for strip samples that are not available in large size. 


\section{S. OSAKI}

Acknowledgement. The author is grateful to Prof. H. Fujita of Osaka University for helpful comments, and also to K. Sakai for help with the measurements.

\section{REFERENCES}

1. S. Osaki, Bull. Jpn. Soc. Print. Sci. Technol., 23, 19 (1985).

2. S. Osaki, Tappi, 70, 105 (1987).

3. S. Osaki, Polym. J., 19, 821 (1987).
4. S. Osaki, J. Appl. Phys., 64, 4181 (1988).

5. K. Yamamoto, S. Osaki, S. Yamashita, and M-O. Yamada, Cell. Mol. Biol., 34, 571 (1988).

6. S. Osaki, J. Appl. Polym. Sci., 37, 527 (1989).

7. S. Osaki and K. Uranishi, Polymer, 31, 33 (1990).

8. S. Osaki, Sen-i Gakkaishi, 46, 26 (1990).

9. S. Osaki, J. Polym. Sci., C, 28, 147 (1990).

10. S. Osaki, J. Appl. Phys., 67, 6513 (1990).

11. S. Osaki, Nature, 347, 132 (1990).

12. S. Osaki, M-o. Yamada, A. Takakusu, and K. Murakami, Cell. Mol. Biol., 39, 673 (1993).

13. N. Marcuvitz, "Microwave Measurements," McGrawHill, New York, N.Y., 1951. 